\title{
SOBRE LA NOCIÓN DE VALIDEZ NORMATIVA
}

\author{
José Juan Moreso \\ Universitat Pompeu Fabra, Barcelona
}

RESUMEN. El artículo es un comentario al trabajo de Ernesto Garzón Valdés: «Algunos modelos de validez normativa» (1977): En él se argumenta que la noción kelseniana de validez jurídica trataba de dar respuesta a dos cuestiones: la cuestión de la pertenencia de las normas al sistema jurídico y la de su fuerza obligatoria. El comentario tiene dos objetivos principales: a) mostrar que, contrariamente a la opinión de Kelsen, se trata de dos cuestiones distintas y $b$ ) que mientras la primera tiene una solución mediante la noción lógica de recursión, la segunda es un problema sustantivo de filosofía práctica.

Palabras clave: Ernesto Garzón Valdés, Hans Kelsen, validez jurídica.

ABSTRACT. The article is a comment on Ernesto Garzón Valdés's paper: «Algunos modelos de validez normativa" (1977). It is argued that the Kelsenian notion of legal validity deals with the answer to two questions: the question of the membership of norms in a legal system and the question of the binding force of legal norms. The aim of the comment is twofold: a) In spite of Kelsen's opinion, these are different questions with different answers and $b$ ) meanwhile the first has a solution by means of the logical notion of recursion, the second is a substantive issue of practical philosophy.

Keywords: Ernesto Garzón Valdés, Hans Kelsen, legal validity. 


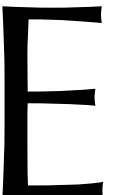

$\mathrm{n}$ un artículo de hace ya tres décadas, cuando algunos de nosotros acabábamos de salir del Instituto de secundaria, Ernesto GARZÓN VALDÉS exponía con lucidez los problemas nucleares a los que cualquier teoría del Derecho debe enfrentarse ${ }^{1}$. Comenzaba exponiendo la posición de Hans KELSEN que constituye el inescapable punto de partida de cualquier teoría jurídica. En realidad, la noción de validez de KELSEN trataba de dar respuesta a dos cuestiones:

a) ¿Qué hace que una norma pertenezca al sistema jurídico? $\mathrm{y}$

b) ¿Qué hace que una norma tenga fuerza obligatoria?

Llamemos al primero el problema de la pertenencia y al segundo el problema de la obligatoriedad. KELSEN consideraba que su teoría ofrecía una única respuesta para ambos problemas. Como es sabido, para KeLSEN la validez de las normas es su modo específico de existir ${ }^{2}$. Y una norma existe si y sólo si su creación ha sido autorizada por otra norma, el fundamento de la validez de una norma ha de ser otra norma ${ }^{3}$. Por otro lado, que una norma existe significa que sus destinatarios han de comportarse como la norma establece ${ }^{4}$. Y dado que la búsqueda del fundamento de validez de una norma no puede conducir al infinito, entonces ha de haber — se ha de suponer que hay- una primera norma, la norma básica, que es el fundamento de validez de todas las normas ${ }^{5}$.

A partir de KELSEN, Ernesto GARZÓN presenta cinco modelos más, que pueden entenderse como variaciones (en el sentido de la filosofía anglosajona de «varieties» ${ }^{6}$, pero también en el francés más frívolo de «varietées») sobre estas cuestiones kelsenianas: el de Francisco SuÁreZ, el de John Austin, el de los representantes de la denominada teoría de la naturaleza de las cosas, el de H. L. A. HART y el de Georg Henrik vON Wright.

En esta breve exposición quiero tan sólo poner de manifiesto que mientras que el problema de la pertenencia, como bien explica Ernesto GARZÓN, tiene una solución conceptualmente plausible, que no es exactamente la de KELSEN; el problema de la obligatoriedad depende de asunciones filosóficas sobre los que hay mucha discrepancia. Y, por lo tanto, quiero subrayar, contra KELSEN, que se trata de dos problemas conceptualmente distintos.

${ }^{1}$ GARZÓN VALDÉs, «Algunos modelos de validez normativa», Revista latinoamericana de filosofía, 3 (197): pp. 41-68, reimpreso en GARZÓN VALdÉs, 1993: Derecho, Ética y Política, Madrid: Centro de Estudios Constitucionales, pp. 73-105, por donde se cita. Una versión abreviada, «Kelsen and Suárez», en PAULSON y LiTsCHEWSKI PAULSON (eds.), 1998: Normativity and Norms. Critical Perspectivas on Kelsenian Themes, Oxford: Oxford University Press, pp. 263-271.

${ }^{2}$ KelSEN, 1960: Reine Rechtslebre, Wien: Franz Deuticke, p. 196.

3 Ibidem, p. 196.

${ }^{4}$ KeLSEN, 1945: General Theory of Law and State, Cambridge, Mass.: Harvard University Press, pp. 115-116.

5 Kelsen, 1960: p. 197.

${ }^{6}$ Véase, por ejemplo, vON Wright, 1963: The Varieties of Goodness, London: Routledge \& Kegan Paul, y Evans, 1953: The Varieties of Reference, Oxford: Oxford University Press. 
No obstante, antes de analizar los dos problemas, quiero aclarar que la idea kelseniana conforme a la cual la validez es el modo específico de existir de las normas presupone una extraña noción de existencia. Sabemos desde la discusión kantiana del argumento ontológico en la Crítica de la razón pura, que la existencia no es una propiedad, que decir de algo que existe (diez táleros en el ejemplo de KANT) no es predicar nada de este algo. Dicho con QUINE: «Ser es ser el valor de una variable» ${ }^{7}$. Es decir que la existencia guarda relación con aquellas entidades que nuestro discurso presupone. Aunque tal vez podría interpretarse la tesis de KELSEN en el sentido de que las únicas normas presupuestas por su teoría jurídica son las normas válidas, esto es, pertenecientes al sistema jurídico y obligatorias.

\section{(3)}

En relación con el problema de la pertenencia, lo primero que hay que decir es que de la afirmación de que la validez de una norma presupone la validez de otra norma que es su fundamento, no se deriva que haya una norma que es el fundamento de todas las demás. Ha sido a menudo señalado que este razonamiento incurre en una fala$\mathrm{cia}^{8}$, la falacia «chico-chica»: de la proposición según la cual todos los chicos quieren a alguna chica no se deriva que haya alguna chica a la que todos los chicos quieren. $\mathrm{O}$, lo que es lo mismo, de la proposición verdadera según la cual todos tenemos un padre no se deriva la falsedad de que haya alguien que es el padre de todos.

En cualquier caso, el problema que KELSEN se plantea, el problema de la definición de norma válida, tiene una solución que consiste en el uso de las definiciones recursivas. La recursividad es un recurso ampliamente usado en lógica y en matemáticas, cuando PEANO definió los números naturales usó una de estas definiciones:

[I] 0 es un número natural,

[II] Todo sucesor de un número natural es también un número natural.

Se estipula que 0 es un número natural y a partir de ello, por recursión, obtenemos el resto de números naturales.

Esto es lo que hace VON WRIGHT con la noción de pertenencia al sistema normativo, ${ }^{9}$ como bien nos recuerda Ernesto GARZÓN ${ }^{10}$. Y esta también es la posición de Carlos E. AlCHOURRÓN y Eugenio BULYGIN en Normative Systems, en donde definen norma válida mediante tres cláusulas ${ }^{11}$ :

a) Todos los enunciados que pertenecen al conjunto C ( $v$. gr. una Constitución) son válidos.

b) Si existe un enunciado válido que autoriza (permite) a una autoridad normativa $x$ formular el enunciado $p, \mathrm{y} x$ ha formulado $p$, entonces $p$ es válido.

${ }^{7}$ VAn Orman Quine, 1953: «On What There Is», From a Logical Point of View, Cambridge, Mass.: Harvard University Press, cap. 1.

${ }^{8}$ Munzer, 1972: Legal Validity, The Hague: Martinus Nijhoff, p. 48, y HernÁNDEZ MARín, 1986: Historia de la filosofía del Derecho contemporánea, Madrid: Tecnos, p. 151.

9 Von Wright, 1963: Norm and Action, London: Routledge \& Kegan Paul, p. 199.

${ }^{10}$ GARZÓN VALDÉS, 1993: p. 100.

${ }^{11}$ AlChOuRRón, y Bulygin, 1975: Introducción a la metodología de las ciencias jurídicas y sociales, Buenos Aires: Astrea, p. 120. 
c) Todos los enunciados que son consecuencia (se infieren) de los enunciados válidos, son válidos.

En resumen, el problema de la pertenencia puede resolverse mediante la noción lógica de recursión.

El problema de la obligatoriedad, en cambio, no puede resolverse tan fácilmente. Si decir que una norma es válida significa que sus destinatarios tienen el deber de comportarse como la norma prescribe, entonces necesitamos una teoría normativa que nos diga cuando estamos obligados a comportarnos de un modo u otro. En mi opinión, el problema de la obligatoriedad tiene únicamente tres soluciones. En primer lugar, puede sostenerse que dicho problema no es tal, que se trata únicamente de un pseudo-problema, porque en realidad no hay nada que sea la obligatoriedad de las normas. Se trata de una posición radicalmente escéptica en materia moral ${ }^{12}$, que ha tenido una gran aceptación en teoría del Derecho ${ }^{13}$.

En segundo lugar, es posible argüir que existe una normatividad jurídica, independiente de la normatividad moral, que hay deberes jurídicos como algo distinto de los deberes morales. Tal vez así pueden reconstruirse algunos aspectos de la teoría de KELSEN: la normatividad del derecho es una normatividad hipotética que depende de la aceptación de la norma básica ${ }^{14}$. A veces, también la teoría de HART es así interpretada, como una normatividad jurídica distinta de la moral, aunque HART también puede interpretarse como una versión sofisticada de AUSTIN: la regla de reconocimiento, en esta interpretación, sólo explica cómo el Derecho funciona y nada dice del problema normativo en sentido estricto.

La tercera posición sostiene que la validez, entendida como obligatoriedad, de las normas jurídicas descansa en su conformidad con la moral ${ }^{15}$. Este es el punto que Francisco SUÁREZ y toda la tradición iusnaturalista enfatizan. Ahora bien, esta tercera posición es compatible con la afirmación de que las normas contrarias a la moral no son válidas, pero también lo es con la afirmación de que las normas válidas contrarias a la moral no son obligatorias. Todo depende de nuestra definición de validez, pero no deberíamos discutir sobre palabras ${ }^{16}$.

${ }^{12}$ Véase, por ejemplo, MACKIE, 1977: Ethics. Inventing Right and Wrong, London: Penguin.

${ }_{13}$ Véase, por ejemplo, la conocida posición de Ross, 1961: en «El concepto de validez y el conflicto entre el positivismo jurídico y el derecho natural», trad. de G. CARRIÓ y O. PECHERO en Ross, A. 1991: El concepto de validez y otros ensayos, México: Fontamara.

${ }^{14}$ Véase, por ejemplo, H. L. A. HART, «Kelsen Visisited», en HART, 1983: Essays in Jurisprudence and Philosophy, Oxford: Oxford University Press, cap. 14, y RAZ, J., «Kelsen's Theory of the Basic Norm», en RAZ, 1979: The Authority of Law, Oxford: Oxford University Press, cap. 7.

${ }^{15}$ Véase, por todos, NINO, 1994: Derecho, moral y política. Una revisión de la teoría general del Derecho, Barcelona: Ariel.

${ }^{16}$ Véase, por ejemplo, GARZÓN VALDÉs, 1990: «Algo más acerca de la relación entre Derecho y Moral», Doxa, 8, pp. 111-130. 